Article

\title{
Effect of EV Movement Schedule and Machine Learning-Based Load Forecasting on Electricity Cost of a Single Household
}

\author{
Stefan Arens *, Karen Derendorf, Frank Schuldt, Karsten von Maydell and Carsten Agert \\ DLR Institute for Networked Energy Systems, Carl-von-Ossietzky-Str. 15, 26129 Oldenburg, Germany; \\ Karen.Derendorf@dlr.de (K.D.); Frank.Schuldt@dlr.de (F.S.); Karsten.Maydell@dlr.de (K.v.M.); \\ Carsten.Agert@dlr.de (C.A.) \\ * Correspondence: Stefan.Arens@dlr.de; Tel.: +49-441-99906-448
}

Received: 23 August 2018; Accepted: 22 October 2018; Published: 25 October 2018

\begin{abstract}
An energy management system (EMS) for a household energy system is proposed in this paper, which is composed of a photovoltaic (PV) generator, a home energy storage (HES), an electric vehicle (EV), an electrical household load and a grid connection, with $24 \mathrm{~h}$ operation horizon. The EMS objective is to reduce the electricity cost of the household by using a linear optimization algorithm. Two different EV schedules are utilized for simulations. One mainly describes rides to work and the other describes rides in a domestic context, such as rides to a supermarket. A forecast algorithm for the electrical load of the household, based on k-means clustering and an artificial neural network, is evaluated and integrated into the EMS to realistically represent the household's load profile. It is shown that the developed forecast algorithm performs better than two of the benchmarks. Another finding is that the more storage is available at PV-production intervals, the higher the effect of forecast uncertainties and the lower the electricity cost of the household, disregarding the investment cost.
\end{abstract}

Keywords: energy management; machine learning; load forecasting; electric vehicle; energy storage

\section{Introduction}

Electric vehicles (EVs) are a promising technology to reduce greenhouse gas emission by substituting fossil fuel based cars. In order to significantly reduce the greenhouse gas emission, electricity from renewable sources should be used to charge the electric vehicle [1]. This can be achieved by using a photovoltaic (PV) generator, which is installed at a household rooftop. This leads to an integrated energy system, comprising of the electricity and the mobility sector. Financial issues are another barrier for a progressing penetration of renewable energy technologies [2]. However, the installation of a suitable energy management system (EMS) enables to reduce cost [3].

In general, an EMS can be used for different system architectures and it can apply varying types of algorithms, whereas input data are often based on forecasts.

An example for the usage of an EMS is to control a system with a PV-generator, a micro turbine, a supercapacitor and a battery, considering a load- and PV-forecast [4]. Van der Meer et al. [5] developed an EMS to control charging processes of EVs, whereas the energy is provided by PV-generators and the grid and additionally a PV-forecast algorithm was integrated. In [6] an optimization of operational cost of an energy system is performed, applying a time of use tariff. Bai et al. [7] investigated power dispatch strategies, considering a load forecast on a virtual power plant with several EVs and also industrial and civil loads. In [8] an EMS is purposed, which utilizes micro economic principles to coordinate components of a microgrid. Heuristic algorithms, like a genetic algorithm, are capable of load scheduling for smart home appliances, reducing peak to average ratio and electricity cost [9]. Anvari-Moghaddam et al. [10] purposed a multi-agent approach for optimizing 
cost and user comfort at a microgrid energy system, containing distributed generation. In [11] a deep reinforcement learning based energy management system was used to operate a microgrind with long-term and short-term storage.

Different energy management algorithms result in significantly different calculation times, raging from several seconds to several hours [12]. Rottondi et al. [13] showed that an energy management system, based on linear programming, can achieve short calculation times within the sub seconds range, while handling several loads and a storage system for an office building, using a load and PV-forecast.

As mentioned energy management is often based on forecasts, depending on the system of consideration. A stochastic investigation of the effect of forecast uncertainties on a microgrid was performed in [14]. However, household electrical load depends on the season, the weather and the occupant behavior [15]. The irregular and very individual consumption pattern of a single household makes forecasting these loads a difficult task [16].

A broad range forecast algorithms have been developed, based on several principles. Artificial Neural Networks (ANNs) can be used for forecasting PV-generation, utilizing weather data. The property of ANNs that no functional relationship of the input and output on an ANN have to be known in advance becomes useful in this case [17]. Time series based, statistical methods like autoregressive moving average (ARMA) and some derivations of ARMA are also capable of performing load forecasts [18]. In [19] a long term load forecast, utilizing fuzzy logic, was purposed. Humeau et al. [16] developed a load forecast algorithm based on linear regression and machine learning tools for single houses and districts. Hernández et al. [20] combined self-organizing maps, k-means clustering and a multilayer perceptron network to predict loads of a town. Ensemble methods, based on decision trees, are capable of performing load forecast for a campus university [21]. Vazquez et al. [22] compared several load forecast algorithms, based on least squares, an elastic net, support vector machines and decision trees. In [23] long short-term memory (LSTM) networks were utilized to perform load forecasts at a household level.

The interaction between a household energy management with different storage options like stationary storage and a mobile storage, while also accounting for the load forecast at a single household system level, has not widely been studied to the authors best knowledge. This is addressed by adding an EV to a household energy system, which provides mobility in varying context. The context is modelled by a primary EV, which is used mainly to get to work and back and by a secondary EV, which is used as a household support vehicle, e.g., going to grocery stores or giving lifts to children. Furthermore, the EV is modelled as a bidirectional system, enabling load balancing services to the household. Thus, additional challenges or opportunities are added for an EMS. These are focused on utilizing the EV storage capacity in an optimal manner and still providing mobility to the household's inhabitants.

To account for forecast uncertainties of the household electrical load, a forecast algorithm, based on k-means clustering and an ANN, is integrated into the EMS. The load forecast algorithm is aimed to be simple, fast and adaptable to a load time series. The forecast algorithm is similar to the one developed by Hernández et al. [20], but simplified and it is applied to time series of single households.

The paper is organized as follows: Section 2 gives information about the simulated system, including the parameters of the components and applied EV schedules. Section 3 describes the household electrical load forecast algorithm, Section 4 shows the optimization and simulation framework, Section 5 describes the results and Section 6 gives a conclusion.

\section{System Description}

The energy system under investigation consists of a PV-generator, a home energy storage system (HES), an electric vehicle (EV), a household load and a grid connection.

\subsection{Energy System}

The system components considered are shown in Figure 1. The energy system is modelled as a load on a single phase. An EV and a HES are added, in order to increase the flexibility of the system. 
Additionally, the EV-battery functions as an energy source for an electric vehicle, thus providing mobility for the household. The inverters and the bidirectional wireless charging device model energy losses due to AC-DC or DC-DC conversions in charging- and discharging processes. The PV-generator feeds energy into the system and the household load drains energy from the system. The grid connection balances potential forecast inaccuracies and is able to supply the system with additional energy or can feed surplus energy into the grid.

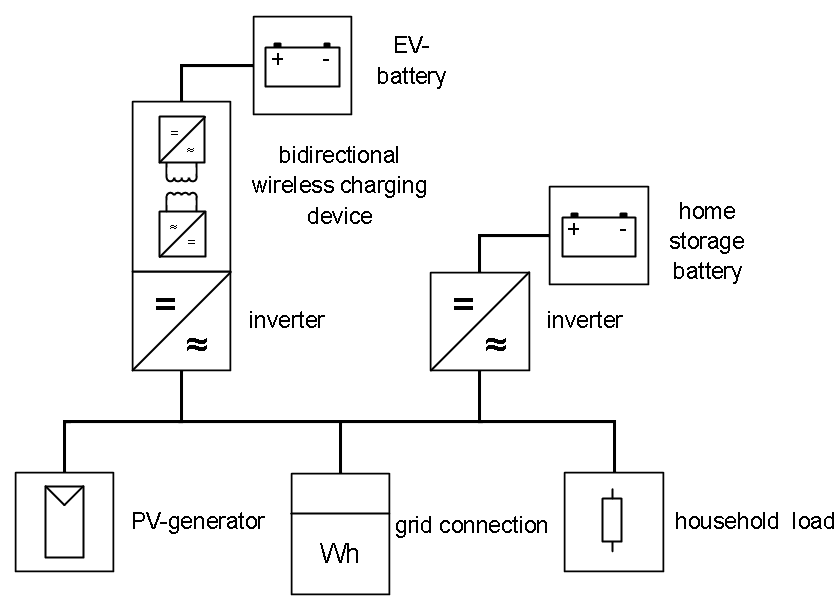

Figure 1. Household energy system.

The household considered in this study has an electricity consumption of $3239 \mathrm{kWh} / \mathrm{a}$. The PV-generator is modelled by a time series of a PV-system, located in Oldenburg, northern Germany, leading to a PV energy production of $4210 \mathrm{kWh} / \mathrm{a}$. The PV time series already takes inverter efficiency into account, which is necessary to convert the DC of the PV generator to the AC of the household electricity grid.

Using energy from the grid is charged with $0.288 € / \mathrm{kWh}$, which is the average cost of electricity of a German household with a consumption of $3500 \mathrm{kWh}$ in 2016 [24]. Feeding energy into the grid generated revenues of $0.123 € / \mathrm{kWh}$, which is the feed in tariff of a PV-system up to $10 \mathrm{kWp}$, build in Germany, at the beginning of 2017 [25].

The EV is assumed to be a microcar, suitable for providing mobility in an area close to a city. It has a rather small capacity of $9.6 \mathrm{kWh}$ and an energy consumption of $10.9 \mathrm{kWh} / 100 \mathrm{~km}$. In order to investigate the stationary storage capacity effect, different HES capacities are simulated, ranging from zero (no HES is used) to $12 \mathrm{kWh}$. The maximal State of Charge (SoC) of the HES and EV is set to $90 \%$, to avoid overcharges. The minimal SoC of the HES is set to $10 \%$, in order to prevent deep discharge. The minimal SoC of the EV is set to $20 \%$, to prevent deep discharge and provide an energy buffer for rides. Maximum powers are defined symmetrically (equal for both directions) for the grid, the HES and the EV. Maximum EV power is set to $10 \mathrm{~kW}$, maximum HES power to $9 \mathrm{~kW}$ and maximum grid power to $40 \mathrm{~kW}$.

Besides losses due to the inverters $\eta_{i n v}$, the bidirectional charging device $\eta_{b i, D C--D C}$, the battery charging efficiencies $\eta_{\text {battery,charge }}$ and battery discharging efficiencies $\eta_{\text {battery,discharge }}$ are taken into consideration. All efficiencies are assumed as constants, to enable usage of a linear optimization based energy management algorithm. This algorithm is introduced in Section 3.2. The inverter efficiency is taken from [26], it represents the efficiency at AC-DC operation at a low output power. Thus, it is a conservative estimation of the efficiency, because according to [26] higher output powers result in higher efficiencies. The efficiency of the bidirectional wireless charging device is assumed to be equal to an unidirectional wireless charging device, with an air gap of $8 \mathrm{~cm}$ and a power of $4 \mathrm{~kW}$ according to [27]. The charging- and discharging efficiencies of both batteries are taken from [28]. They are determined at a current of $1.5 \mathrm{C}$ and a state of charge $(\mathrm{SoC})$ of $10 \%$. An overview of considered efficiencies and its values is given in Table 1. 
Table 1. Relevant efficiencies for the household energy system.

\begin{tabular}{cc}
\hline Efficiency & Value \\
\hline$\eta_{\text {inv }}$ & 0.93 \\
$\eta_{b i, D C-D C}$ & 0.966 \\
$\eta_{\text {battery, charge }}$ & 0.967 \\
$\eta_{\text {battery, discharge }}$ & 0.961 \\
\hline
\end{tabular}

To simplify calculations, several efficiencies of single components are combined to efficiencies for every relevant process (i.e., discharging/charging the HES or EV), according to (1)-(4).

$$
\begin{gathered}
\eta_{H E S}^{+}=\eta_{\text {inv }} \eta_{\text {battery,discharge }} \\
\eta_{H E S}^{-}=\eta_{\text {inv }} \eta_{\text {battery,charge }} \\
\eta_{E V}^{+}=\eta_{i n v} \eta_{b i, D C-D C} \eta_{\text {battery,discharge }} \\
\eta_{E V}^{-}=\eta_{i n v} \eta_{b i, D C-D C} \eta_{b a t t e r y, \text { charge }}
\end{gathered}
$$

\subsection{EV Schedules}

Two schedules are conceived to model the EV-usage. The first schedule is focused on rides from and to the working place. Additionally, trips of variable lengths at the weekend are added, which model EV-usage within spare time. This schedule is called primary EV schedule. The other schedule simulates an EV used for household support. Trips within this schedule simulate bringing or picking up children to and from kindergarten and occasional trips, associated with shopping or social activity. At weekends it is assumed that another vehicle is used for potential rides. This schedule is called secondary EV schedule. Table 2 shows general aspects of both EV schedules. It indicates that the primary EV schedule consisted of less, but bigger distance rides compared to the secondary EV schedule. Details about the EV schedules are given in the Appendix A.

Table 2. EV schedule characteristics.

\begin{tabular}{ccc}
\hline Schedule & Primary & Secondary \\
\hline Total distance $(\mathrm{km} / \mathrm{a})$ & 9775 & 5570 \\
Number of rides & 333 & 637 \\
\hline
\end{tabular}

The primary EV schedule leads to a profile whereas the EV is mostly not available during the day because the EV is parked at the working place. The secondary EV-profile results in the EV being at the household most of the time. Potential trips of the secondary EV schedule are not only short in distance but also short in duration.

\section{Forecast Algorithm}

This section describes a forecast algorithm for electric household load, which is integrated into the EMS as input data. The forecast algorithm aims to determine typical one-day electricity consumption patterns of a single household. To achieve this, a clustering algorithm is applied to electrical load time series of that particular household. A further step investigates the chronology of these consumption patterns.

\subsection{Procedure}

The consumption patterns are determined by applying the k-means algorithm, utilizing the Manhattan-distance function, implemented in the Waikato Environment for Knowledge Analysis 
(WEKA)-software [29]. The Manhattan-distance function is preferred over the widely used Euclideandistance function, since it resulted in a lower MAPE. The resulting cluster centers, gained by the k-means algorithm, represent the generalized electrical load profiles of the household. One day is divided into 9615 -min intervals, shaping a single data point into $\mathbb{R}^{96}$. The algorithm itself aims to allocate $\mathrm{N}$ of these data points to $\mathrm{k}$ clusters. Every cluster center, gained from the k-means algorithm, is also described by a vector in $\mathbb{R}^{96}$. The number of clusters $\mathrm{k}$ has to be predetermined before running the $\mathrm{k}$-means algorithm. In this study, $\mathrm{k}$ is aimed in such that the household load time series is described as precise as possible while using as less clusters as possible. Thus, generalized, typical daily loads are determined from the training data.

An ANN is utilized to learn the temporal structure of days allocated to a certain cluster. The ANN is used, due to is capability to handle categorical features, such as our cluster approach and modelling complex non linear dependencies between them. It is programmed by usage of the Encog Machine Learning Framework [30].

Every neuron in the input or output layer is responsible for one cluster of a particular day. The ANN is used to forecast the cluster of the next day, based on the past three days. In the input-layer, the neuron responsible for the allocated cluster of the respective day is set to an activation of one; all other neurons of that day are set to an activation of zero. The neuron with the highest activation in the output layer determined the cluster which is forecasted.

\subsection{Hyperparameter Estimation}

The hyper parameters are determined by performing a grind search over the number of clusters $\mathrm{k}$ and the number of neurons in the hidden layer, whereas only single hidden layer ANNs are considered. Additionally, a ten-fold cross-validation is applied. One of these ten folds is used as testing data, the other folds are used to train the model. Every fold is used as testing data once. From these ten runs, the mean and standard deviation (STD) of the mean average percentage error (MAPE) results are calculated. The results of the hyper parameter estimation are shown in Figure 2. It can be seen that a high number of neurons in the hidden layer lead to poor mean MAPE, which is explained due to overfitting. The number of clusters $\mathrm{k}$ results in good mean MAPE with $\mathrm{k}=6, \mathrm{k}=9$ and $\mathrm{k}=17$. However, if additionally the standard deviation is considered, it can be seen that a combination of six clusters and eight neurons in the hidden layer results in low average MAPE and also exhibits a relatively low STD.

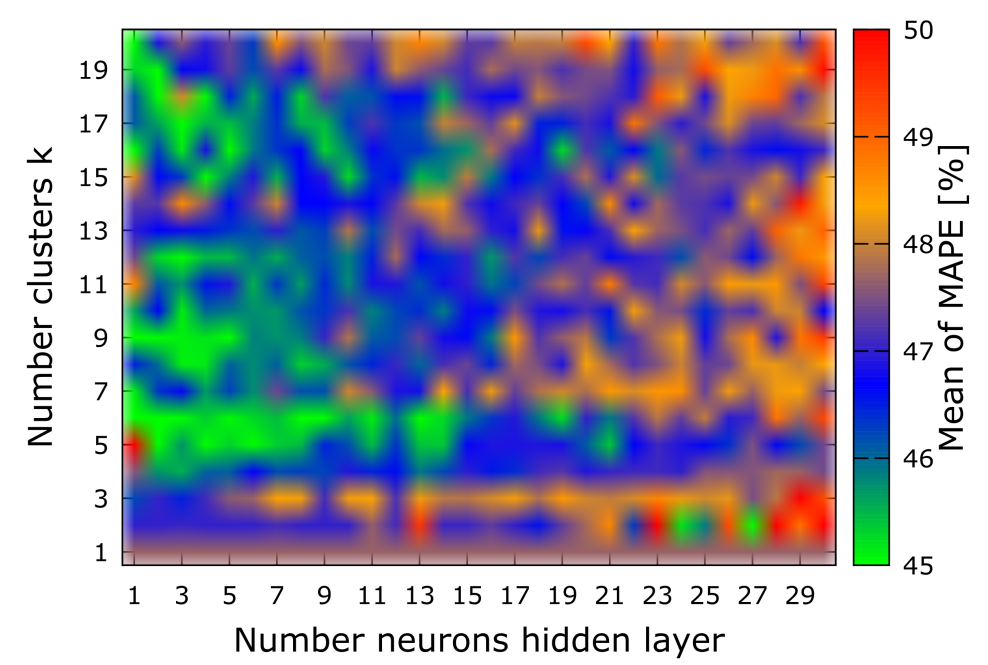

(a) Cont. 


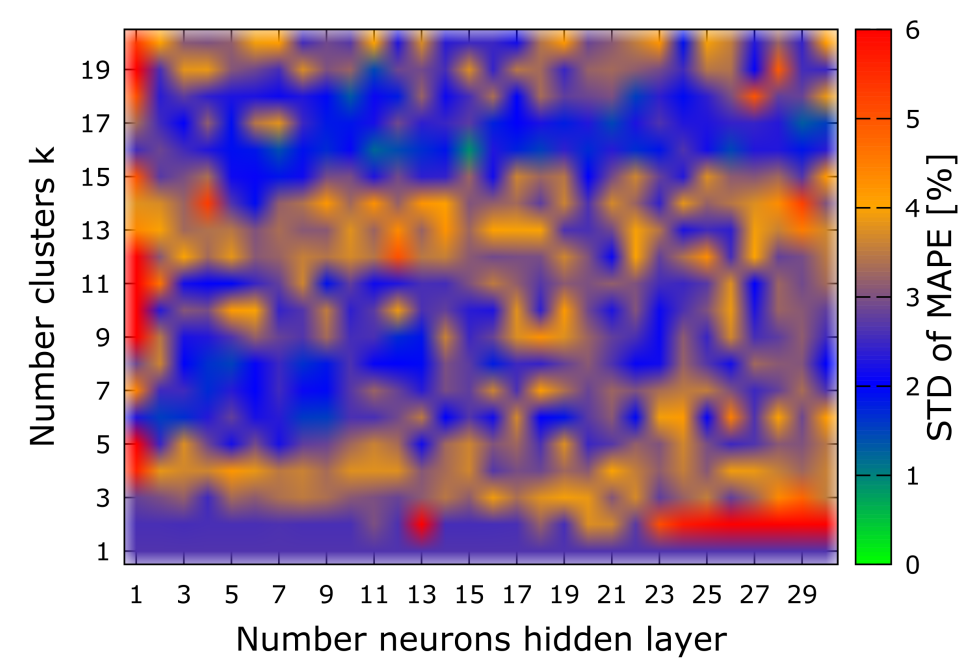

(b)

Figure 2. MAPE results of grid search, mean (a) and (STD) (b).

Figure 3 shows the final structure of the used feed forward, single hidden layer ANN. The network consists of 18 neurons in the input layer, eight neurons in the hidden layer and six neurons in the output layer; it is fully connected. As mentioned before, every neuron in the input or output layer is responsible for one cluster of a particular day and every cluster is marked with a certain color. Because one day can be allocated to six different clusters, six different colors are used.

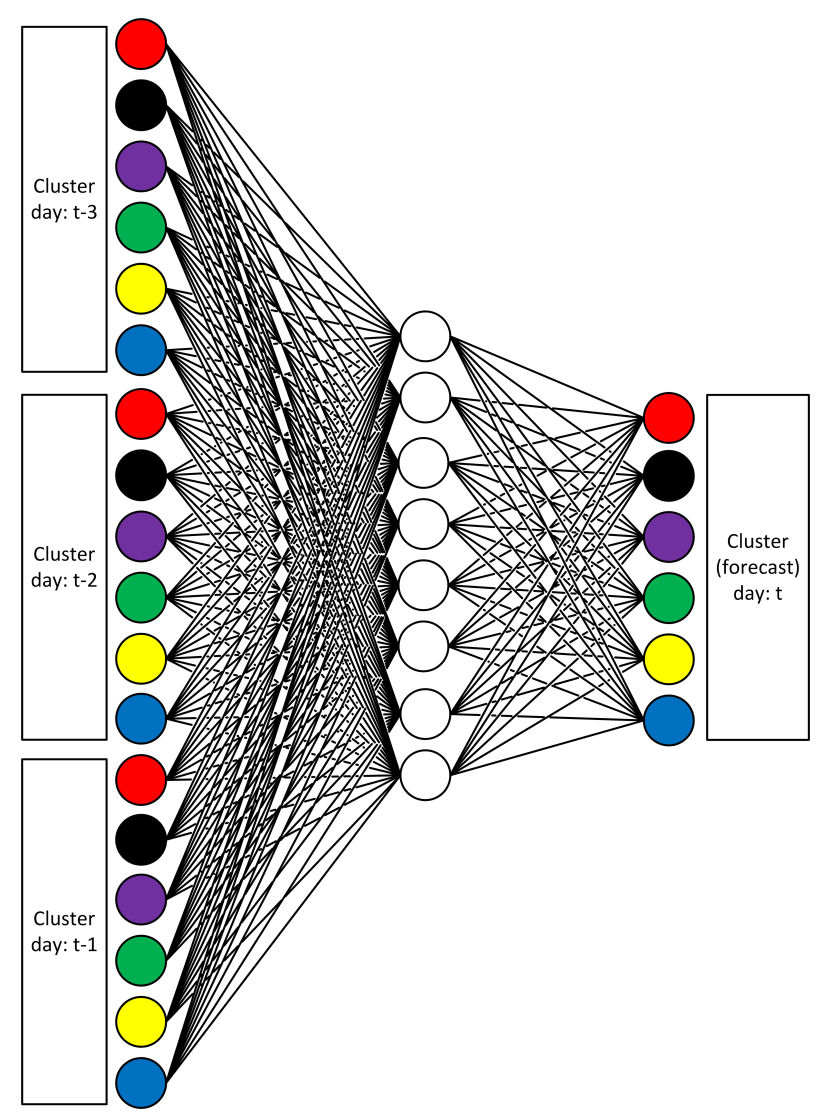

Figure 3. Structure of the ANN. 


\subsection{Load Forecast Evaluation}

To evaluate the load forecast algorithm, the chosen parameter results are compared to benchmarks, which also are calculated based on the testing data from the cross validation. The two benchmarks are called persistence (1) and persistence (2). Persistence (1) predicts a new day equal to the last day. Persistence (2) predicts a new day equal to the last same weekday, e.g. the next Monday is equal to the last Monday. Persistence (1) is chosen because it basically is the simplest forecast procedure one can think of to perform a forecast for a whole day. Persistence (2) is a simple approach to catch consumption patterns of the household, which are repeated weekly. Additionally, the forecast results are compared to another forecast, which works on a lower temporal resolution, called minute wise forecast. It predicts the next minute based on the last minute. Besides the previously applied MAPE, the root mean square error (RMSE) and the mean bias error (MBE) supplement the load forecast evaluation. Figure 4 shows the results. The forecast algorithm achieves lower RMSE and MAPE compared to persistence (1) and persistence (2). Note the persistence (1) and persistence (2) show almost the same averaged errors. The MBE of the forecast algorithm is negative, indicating a tendency to underestimate values. It is found that the results from the forecast algorithm do not vary significantly in terms of RMSE and MAPE. Only the MBE exhibits bigger variations. Comparing the developed forecast algorithm to the minute wise forecast, it is shown that the developed forecast algorithm results in higher average forecasting errors.

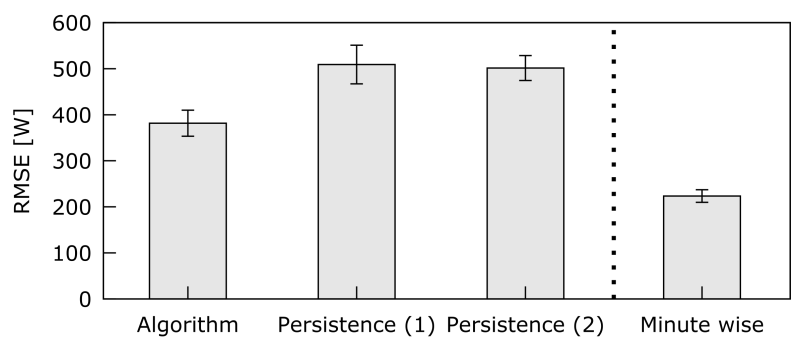

(a)

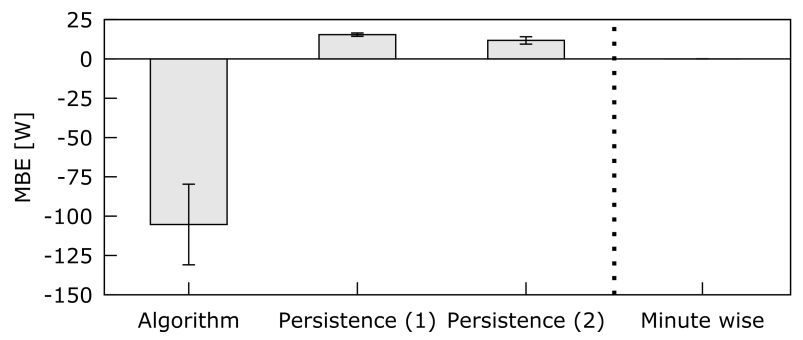

(b)

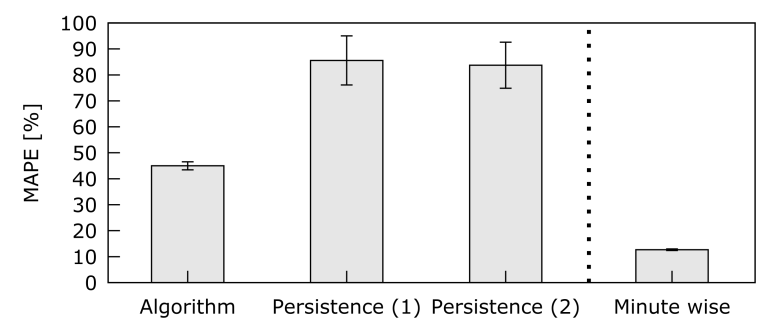

(c)

Figure 4. Error characteristics RMSE (a), MBE (b) and MAPE (c) of the forecast algorithm compared to three different benchmarks. 


\subsection{Updating Training Data Pool}

In reality time progresses steadily and the only available training data are from the past. Additionally, an online learning capability of the forecasting algorithm is desired. In case consumption pattern change, for example due to seasonal variation, the forecast algorithm can account for the change rapidly due to the online learning capability. A limited training pool is introduced for retraining the algorithm, at reduced computational cost. This training pool is constantly updated with the most current day electricity consumption data. The first seven days of the year are used for initially building the cluster centers and training the ANN. Afterwards, the next day is forecasted, the error calculated and the previous day is added to the training data pool. This is repeated for the remaining days of the year. If the training data pool exceeded a certain threshold, the oldest data point is removed from the training date pool. The procedure is repeated with different maximal training pool sizes.

In Figure 5 the results are shown. Increasing the number of days in the training data pool leads to a decrease of the RMSE and the MAPE. Furthermore, increasing the training data pool increases the absolute value of the MBE. Because the RMSE and MAPE do not decrease significantly after increasing the training pool to more than 30 days, these 30 days are chosen to be a reasonable number of training data within the training pool. Additionally, using a rather small training data pool results in low computational effort, which is associated with building the cluster centers and training the ANN.

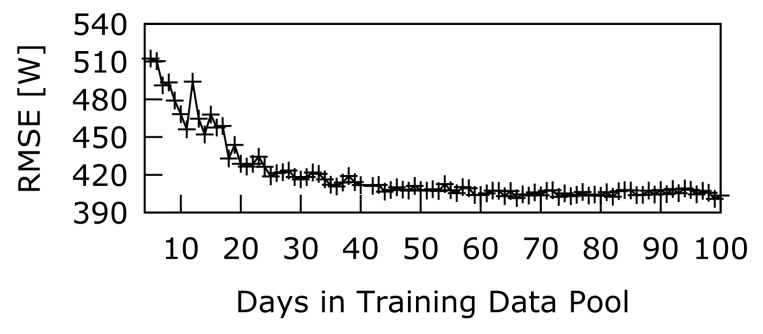

(a)

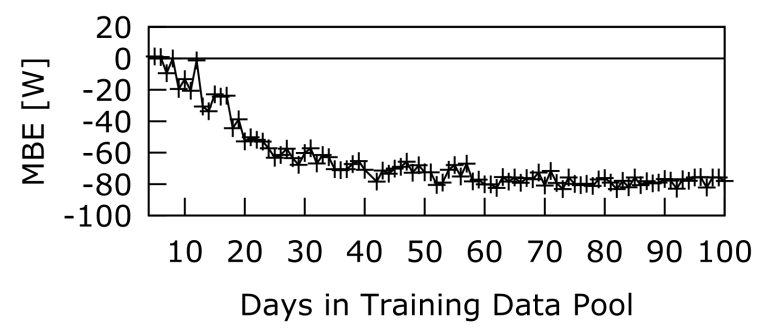

(b)

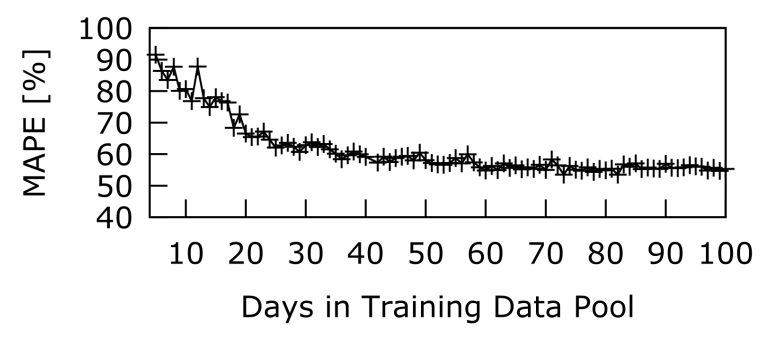

(c)

Figure 5. Error characteristics RMSE (a), MBE (b) and MAPE (c) for using different training data pool sizes. 


\section{EMS}

In this study, the EMS manages charging and discharging of the HES and the EV. Its main purpose is to reduce the electricity cost of a household.

\subsection{Temporal Structure and Forecast Integration}

The developed household load forecast algorithm is integrated into the energy management system, because it performs more precise in average than the persistence benchmarks on a longer time scale, which is shown in Section 3. Although, on the shorter time scale the minute wise forecast technique shows better results. To enable as accurate energy management as possible, the minute wise forecast and the developed forecast algorithm are integrated into the EMS, according to Figure 6 . Therefore, combinations of one- and 15-min intervals are used by the EMS. The first one-minute interval, indicated in blue, is filled with the persistence forecast of the household load. The following grey intervals are filled with the forecasted cluster center value of the respective time interval. The number of minute intervals is variable, to enable the integration of the minute wise forecast and still providing the 15-min interval structure of the developed household load forecast algorithm.

The PV-forecast followed the same temporal structure as described in Figure 6. However, no forecast algorithm is implemented to generate the PV-input for the EMS. The values used by the EMS are the actual PV generation values. In consequence, the PV-forecast is treated as a perfect forecast with no forecasting errors. This enables to focus on the effect of the household forecast on the electricity cost. Additionally, the EV-trips are assumed to be perfectly known beforehand, which can be interpreted as a user who plans every ride $24 \mathrm{~h}$ in advance and forwards the information to the EMS.

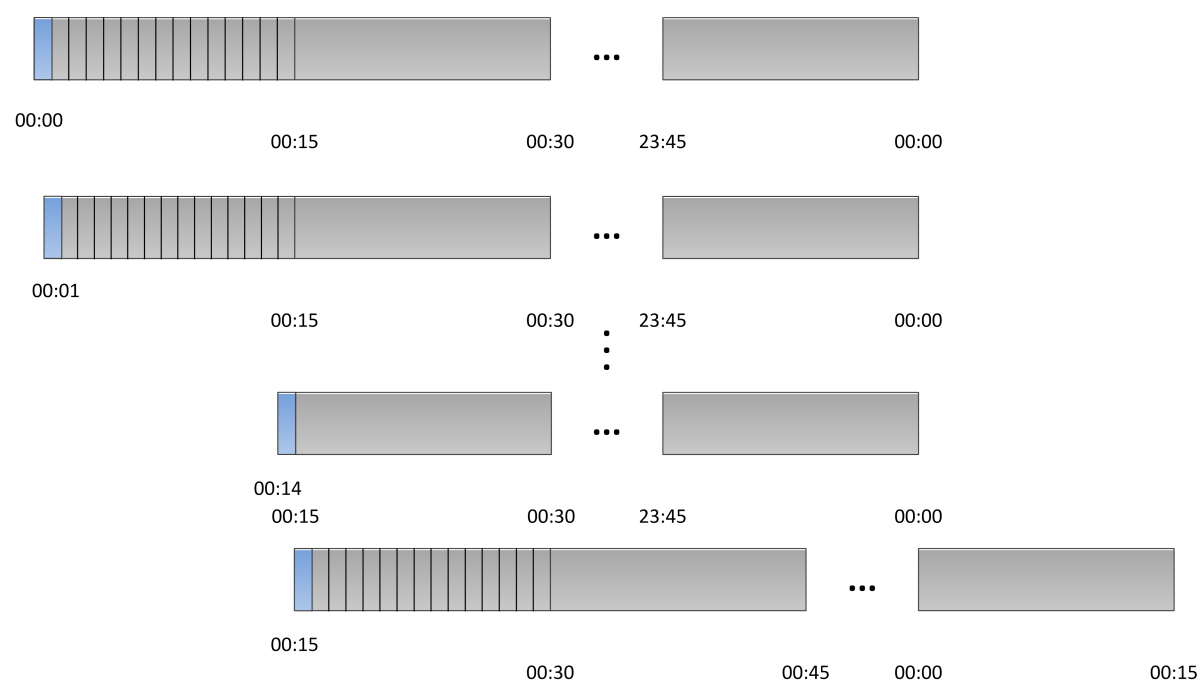

Figure 6. Temporal structure of the EMS due to the integration of the household electrical load forecast.

\subsection{Linear Optimization Algorithm}

The EMS used in this study aims to reduce the electricity cost of a household by means of a linear optimization algorithm.

Let $T_{p}=\left\{t_{1}, t_{2} \ldots t_{N}\right\}$ be a set of discrete points in time, whereas every $j$-th time interval is defined according to: $\Delta t_{j}=t_{j}-t_{j-1}$. Also let $T=\left\{\Delta t_{1}, \Delta t_{2} \ldots \Delta t_{N-1}\right\}$ be a set of all time intervals, $T_{E V=\text { true }}$ a set of all time intervals with the EV being available at the household, ready to be charged or discharged and $T_{E V=f a l s e}$ a set of all time intervals whereas the EV is not available at the household.

Equations (5)-(19) follow a similar approach as [5,13], but are adapted to meet the requirements of the system under investigation and the optimization framework. The equations are solved by means of the GNU linear programming kit (GLPK) [31] The objective function is defined according to (5) and (6). As mentioned, the optimization aims to reduce the electricity cost of the household, which are mainly 
described by the first two terms of (5). The first term describes the cost due to electricity usage from the grid and the second term generates revenues for feeding energy into the grid. The next two terms are used to shift charging and discharging of the HES to earlier times in the simulation. This is found to decrease the electricity cost over the course of the simulation. The last term stimulates charging the EV earlier, which increases the flexibility of the EV, because more energy is available at earlier time intervals. It has to be noted that all optimization variables are set to be bigger than zero. Equation (7) defines the energy balance. Equations (7) and (8) make sure that SoC limitations are followed during the optimization. Equation (10)-(19) define the valid range of the optimization variables, introducing the SoC limitation and the power limitations. Note that Equation (11) is used to account for EV-usage. The SoC limitations of the EV are adjusted by the desired energy demand around departure time.

$$
\begin{aligned}
& \min \left(\sum_{j \in T} \Delta t_{j} \text { PoE } P_{g r i d, j}^{+}-\sum_{j \in T} \Delta t_{j} \text { FiT } P_{\text {grid }, j}^{-}\right. \\
& \left.-\sum_{j \in T} \Delta t_{j} s t f_{j} P_{H E S}^{+}-\sum_{j \in T} \Delta t_{j} s t f_{j} F i T_{j} P_{E V, j}^{-}-\sum_{j \in T} \Delta t_{j} s t f_{j} F i T_{j} P_{E V, j}^{-}\right) \\
& s t f_{j}=\left\{\begin{array}{rll}
0.0001 & \text { if } & \Delta t_{j}=60 s \\
0 & \text { else }
\end{array}\right.
\end{aligned}
$$

Subjected to:

$$
\begin{aligned}
& P_{\text {house }, j}-P_{P V, j}=P_{H E S, j}^{+}+P_{E V, j}^{+}+P_{g r i d, j}^{+}-P_{E V, j}^{-}-P_{H E S, j}^{-}-P_{g r i d, j}^{-} \forall j \in T \\
& S o C_{H E S, j}=\frac{1}{E_{H E S, t o t a l}} \sum_{i=1}^{j}\left(-\frac{1}{\eta_{H E S}^{+}} P_{H E S}^{+} \Delta t_{i}+\eta_{H E S}^{-} P_{H E S}^{-} \Delta t_{i}\right) \forall j \in T \\
& \operatorname{SoC}_{E V, j}=\frac{1}{E_{E V, \text { total }}} \sum_{i=1}^{j}\left(-\frac{1}{\eta_{E V}^{+}} P_{E V}^{+} \Delta t_{i}+\eta_{E V}^{-} P_{E V}^{-} \Delta t_{i}\right) \forall j \in T \\
& S_{\text {SoC }} C_{H E S, \text { min }} \leq S o C_{H E S, j} \leq S o C_{H E S, \max } \forall j \in T \\
& \operatorname{SoC}_{E V, \min , j} \leq \operatorname{SoC}_{E V, j} \leq \operatorname{SoC}_{E V, \max , j} \forall j \in T \\
& 0 \leq P_{\text {grid }, j}^{+} \leq P_{\text {grid, max }}^{+} \forall j \in T \\
& 0 \leq P_{\text {grid }, j}^{-} \leq P_{\text {grid, }, \text { max }}^{-} \forall j \in T \\
& 0 \leq P_{H E S, j}^{+} \leq P_{H E S, \max }^{+} \forall j \in T \\
& 0 \leq P_{H E S, j}^{-} \leq P_{H E S, \text { max }}^{-} \forall j \in T \\
& 0 \leq P_{E V, j}^{+} \leq P_{E V, \text { max }}^{+} \forall j \in T_{E V=\text { true }} \\
& 0 \leq P_{E V, j}^{-} \leq P_{E V, \text { max }}^{-} \forall j \in T_{E V=\text { true }} \\
& P_{E V, j}^{+}=0 \forall j \in T_{E V=\text { false }} \\
& P_{E V, j}^{-}=0 \forall j \in T_{E V=\text { false }}
\end{aligned}
$$

\subsection{Simulation Procedure}

Figure 7 shows the simulation procedure in more detail. The initializing phase comprises the first seven days of a year. These days are used to initially build the clusters and train the ANN. For the actual simulations, at first a forecast for the household load is performed. The optimizer uses this forecast plus the data for PV-power and EV movement to perform power scheduling. The scheduling results are extracted and according to these the new SoCs of the HES and the EV are calculated. Additionally, 
a new electrical load data-point becomes available for the algorithm at that point. With the new data, a new forecast is performed if the added data does not finish a day. Otherwise, the recently finished day is used to update the training data pool, which then is used to retrain the forecast algorithm. The simulation stops after the 364th day of the year, which means in total 357 days are simulated. It was chosen not to alter the time series artificially in order to make simulations for 365 days, which would have meant to add eight days. During simulations, the grid functions as a balancing system. If an energy imbalance occurs due to an erroneous forecast or production and generation inequalities, the imbalance is corrected by adjusting the power of the grid.

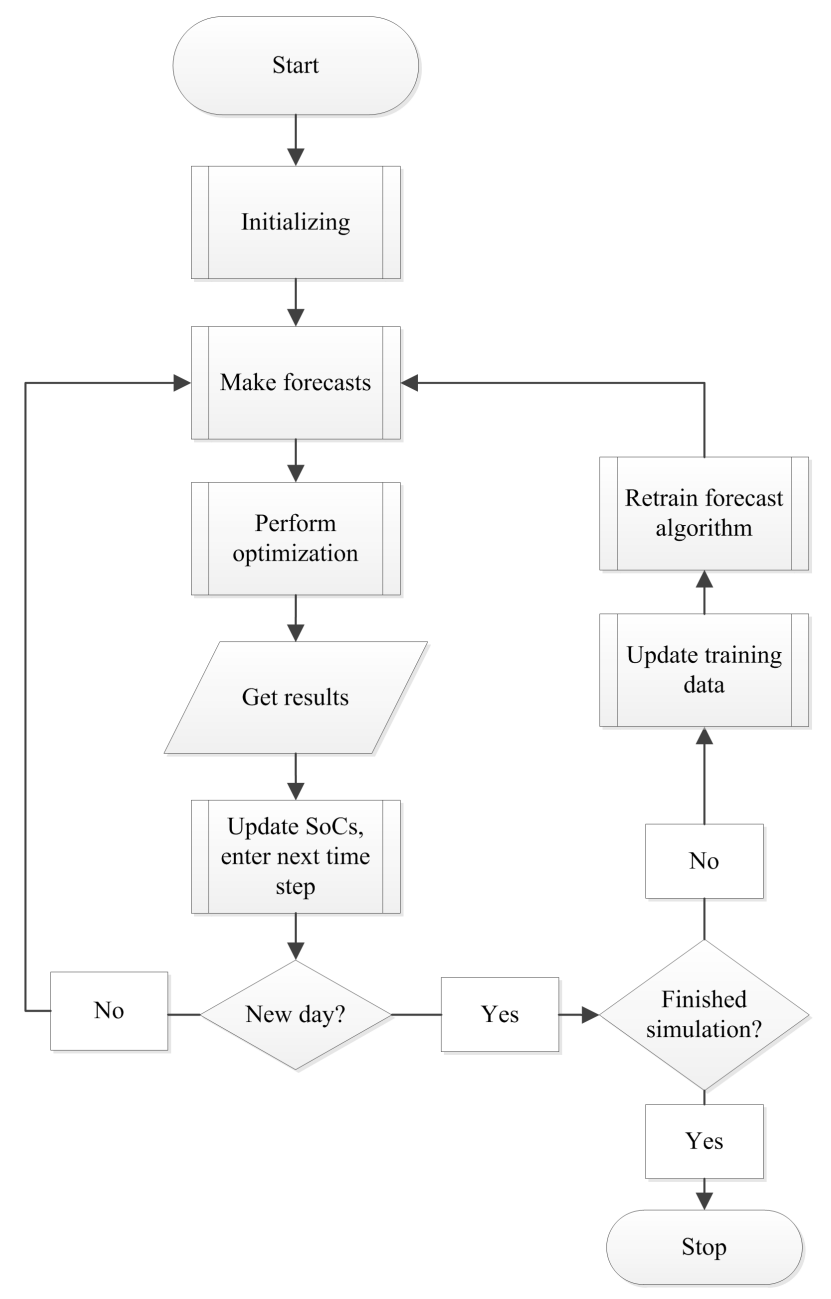

Figure 7. Simulation scheme.

\section{Simulation Results}

The results are investigated using two different EV schedules. The primary schedule described trips from and to work, complemented by occasional trips at weekends. The secondary schedule describes the EV as a household supplement within the week. The effect of load forecast uncertainties is investigated using these different EV schedules and finally a cost analysis is performed. Household electricity cost are calculated from grid energy flow, which results in cost or revenues depending on the direction of power flow.

\subsection{Effect of Prediction Errors}

Erroneous load forecast increase the electricity cost of the household due to imperfect utilization of the storage devices. If an erroneous forecast leads to an overestimation of the load and the 
overestimated load is supplied by a storage system, the grid will take the surplus energy. In this case, the household receives a revenue according to the FiT. However, the the PoE is bigger than the FiT. Because of this difference, it is more beneficial to supply future household load with stored energy than to feed the energy into the grid. If the load forecast is too low, the additional energy demand is balanced by the grid. The difference could have been supplied by a storage device if enough energy is available at the respective device, thus reducing to overall cost. The effect of forecast uncertainties are investigated applying both EV schedules to the system with variable HES capacities. Simulations, using the forecast procedure introduced in section three and simulations using the actual load values (a perfect forecast), are carried out to investigate to effect of load forecast errors. The results are shown in Figure 8. In general, the bigger the HES capacity, the bigger the difference between a perfect forecast and a forecast with prediction errors is. The primary EV shows a steeper increase of the difference as the HES capacity increased. Using the EV as a secondary vehicle results in higher differences in general. Additionally the difference does not increases significantly if the HES capacity exceeds $3 \mathrm{kWh}$ in case of the secondary EV.

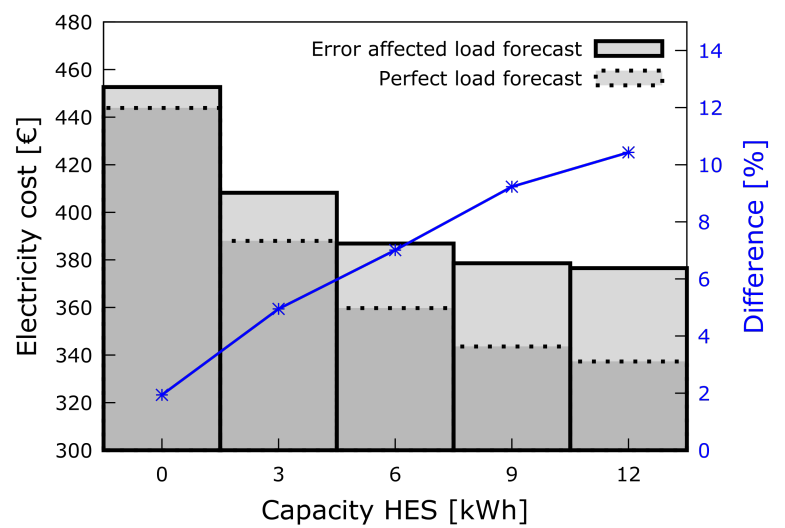

(a)

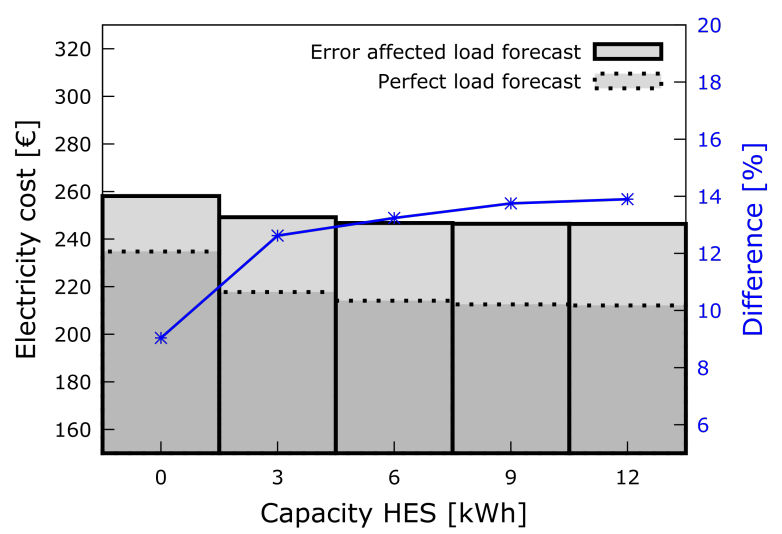

(b)

Figure 8. Simulation results from using the EV as a primary vehicle (a) and as a secondary vehicle (b).

The second source of uncertainty arises due to PV-forecast errors. The influence is investigated by adding a last day persistence PV-forecast besides the load forecast. The results are listed in Table 3. It is shown that the PV forecast has a similar effect as the load forecast. As the HES capacity increase also the cost increase, especially for the primary EV. The secondary EV shows less dependency on the installed HES capacity. 
Table 3. Comparison: Load forecast and Load + PV forecast.

\begin{tabular}{ccccc}
\hline \multirow{2}{*}{ Capacity HES (kWh) } & \multicolumn{2}{c}{ Cost Primary EV Schedule $(€)$} & \multicolumn{2}{c}{ Cost Secondary EV Schedule $(€)$} \\
\cline { 2 - 5 } & Load Forecast & Load + PV Forecast & Load Forecast & Load + PV Forecast \\
\hline 0 & 452.66 & 469.58 & 258.11 & 279.74 \\
3 & 408.18 & 430.78 & 249.20 & 274.13 \\
6 & 386.87 & 415.21 & 246.78 & 271.64 \\
9 & 378.57 & 408.65 & 246.43 & 271.42 \\
12 & 376.55 & 407.27 & 246.38 & 271.27 \\
\hline
\end{tabular}

\subsection{Effect of EV Schedule}

Figure 9 shows the general behavior of both EV schedules. It can be seen that the primary EV (left side) is mostly not available when PV-power is available. Therefore, it is not possible to utilize the PV-power by storing it in the EV battery. The EV basically adds an additional load to the system, indicated by the big power to charge the EV via discharging the HES. On the right side, the results from using the EV as a secondary vehicle are shown. In contrast to the primary EV, the secondary EV is available during sections of the day with PV-generation. During this time the EV-battery is charged with available PV-power. It also acted as a storage device, by discharging the EV during the evening and night, utilizing the bidirectional technology.

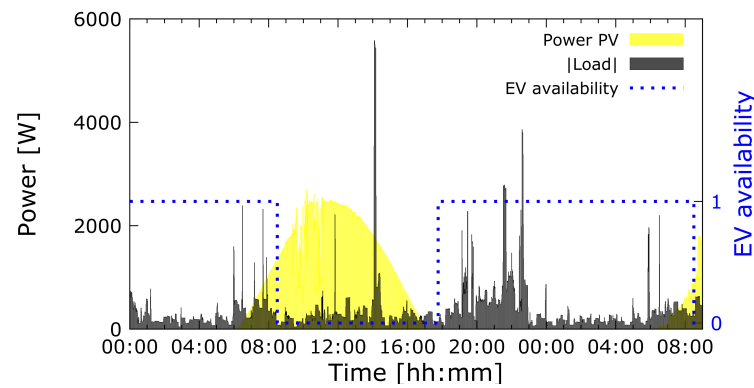

(a)

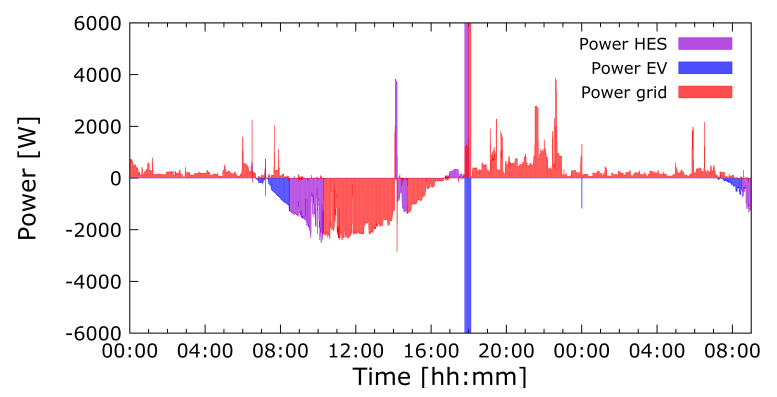

(c)

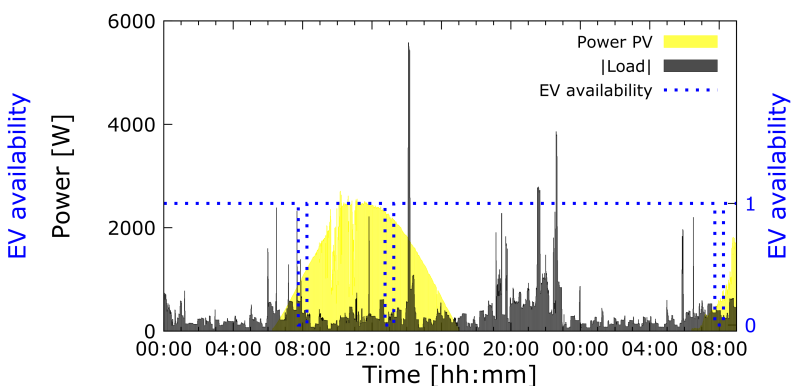

(b)

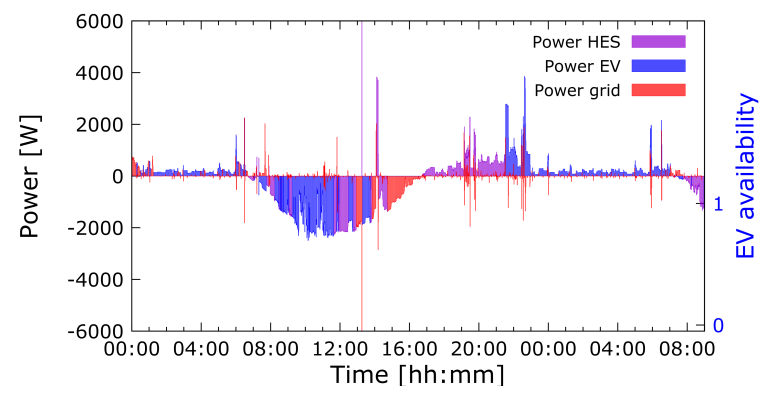

(d)

Figure 9. Comparison between primary and secondary EV schedule results. In the top figures the relevant time series are shown, (a) shows the primary vehicle, (b) shows the secondary vehicle. The bottom figures show the allocated power, (c) shows the primary vehicle, (d) shows the secondary vehicle. A negative value means the HES or EV is charged, a positive value means the respective component is discharged. In red the balancing power from the grid is shown. A negative value means that power is fed into the grid, a positive values means that power is gained from the grid.

In this study the household with a primary EV is assumed to have no other vehicle which contributes to the electricity cost. The household with a secondary EV is assumed to have another fossil fuel based car, however, the gasoline cost are not included in this cost analysis. 
The secondary EV models a mobility pattern resulting to a distance of $5570 \mathrm{~km} / \mathrm{a}$, and the primary EV models a mobility pattern resulting to a distance $9775 \mathrm{~km} / \mathrm{a}$. To account for the bigger total distance of the primary EV schedule, the secondary EV schedule results are augmented by a lump-sum, which is calculated according to (20). The lump-sum assumes that the secondary EV uses only electricity from the grid for the additional distance, although charging efficiency is neglected. However, if power from the PV-generator has been used, lower additional cost would have been added.

$$
\Delta C_{\text {schedule }}=\left(L_{E V, \text { primary }}-L_{E V, \text { secondary }}\right) E_{E V, \text { ride }} \text { PoE }
$$

In Figure 10, the cost for the household using the EV as a primary vehicle, using it as a secondary vehicle and the lump-sum augmented secondary EV cost are shown. Each system is simulated with different stationary storage capacities. In general, the secondary EV results in lower cost than the primary EV, especially because less energy is needed to supply the EV. The difference between the primary and secondary schedule is decreased by applying the lump-sum for the different schedule distance to the secondary schedule. Taken the lump-sum into account, the secondary EV schedule still results in lower cost, especially at lower HES capacities. However, increasing the capacity of the HES brings the cost to an almost even number at $12 \mathrm{kWh}$. This means, a secondary EV can act as a stationary storage device to reduce electricity cost. Using the secondary EV with bidirectional technology has a similar effect as adding stationary storage to household. It increases the capability of the system to utilize PV-power for load applications.

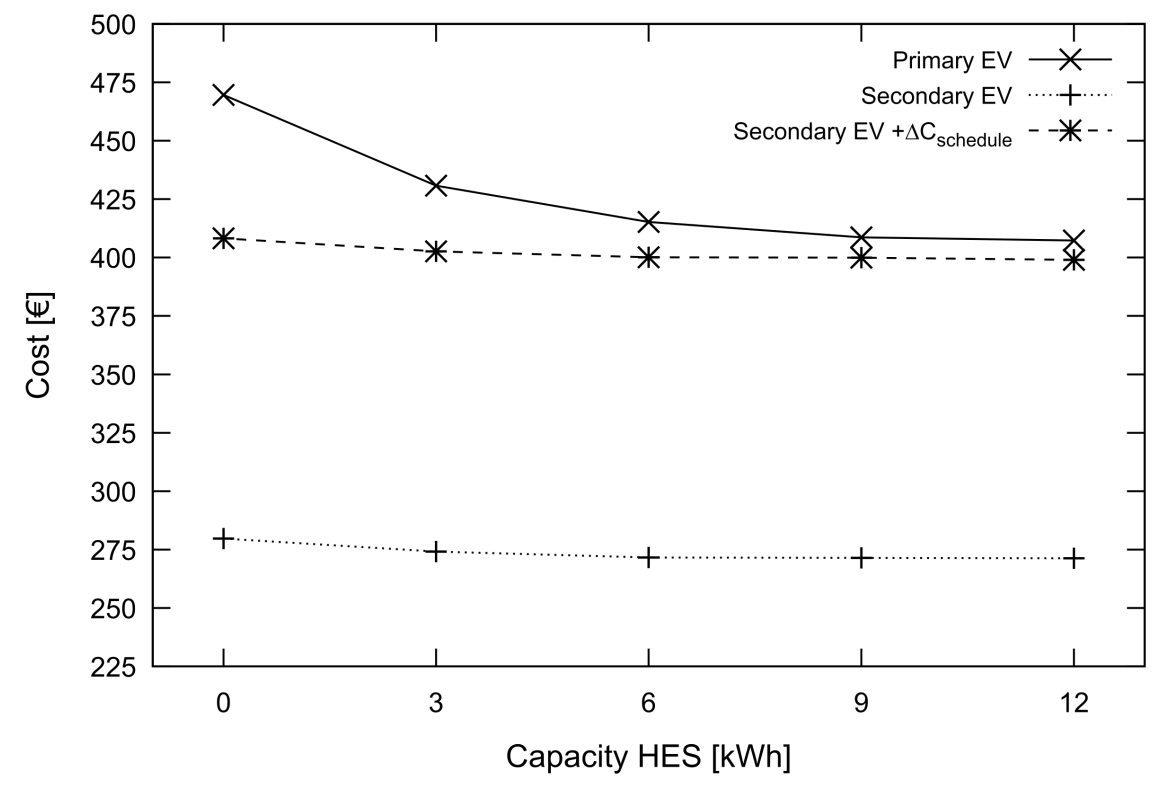

Figure 10. Total electricity cost gained from simulations and by applying the lump-sum.

The positive effect of using an EV as a secondary vehicle can also be observed by investigating payback times. The payback time is calculated via dividing the system cost by the cost savings per day. The savings correspond to the difference in electricity costs between a household without a PV generator and HES and a household with a PV generator and HES. The PV-system price is calculated assuming a PV-system cost of $935 € / \mathrm{kWp}$ [32]. The total cost of the PV-system is $4675 €$. The HES cost is estimated to be $1300 € / \mathrm{kWh}$ [33].

In Figure 11 the payback times are shown, considering only components which refer solely to the electricity system, i.e., PV and HES. The secondary EV results in lower payback times, especially at HES capacities up to six $\mathrm{kWh}$, compared to the same system with a primary EV-usage schedule. Adding stationary storage capacities reduces the positive effect of the secondary EV schedule. 
Reaching $12 \mathrm{kWh}$, no significant difference can be observed. Additionally, the HES cost are a mayor factor. Increasing the HES-capacities greatly increase the payback time, which states true for both applied schedules.

Moreover, the EV needs to be considered. But the EV is not solely part of the electricity system. It also provides mobility and can function a prestige object [34]. If a cheap EV, with cost of $16,000 €$ is assumed and no monetary benefit due to mobility services are added, the payback time would increase in a range of 6400-7400 days, depending on the HES capacity. This means, the car needs to have a lifetime of around twenty years, without the requirement of maintenance, to justify its investment as a saving measure for electricity cost. Nevertheless, if an EV is considered as absolutely necessary, due to its provided mobility to the household and it has a secondary schedule instead of a primary schedule, the payback time of the electricity system components is reduced.

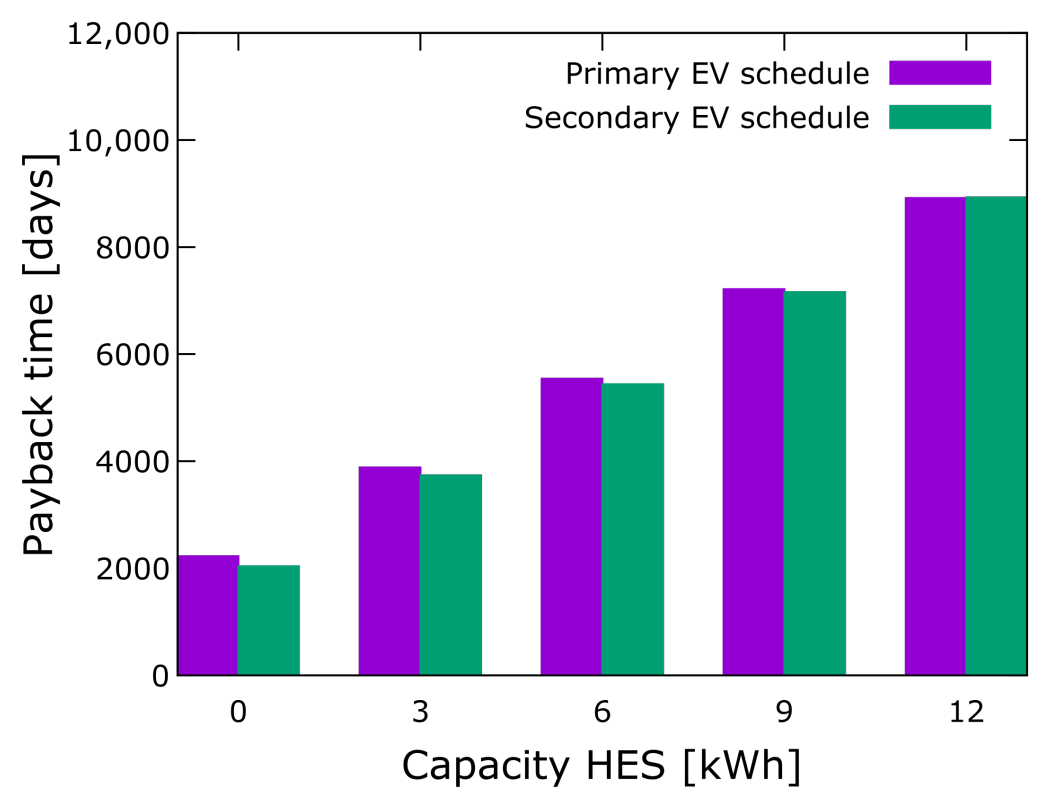

Figure 11. Payback time of the energy system, disregarding EV investment cost.

\section{Conclusions}

In this paper a forecast algorithm for electrical loads is developed and integrated into an energy management system. The energy system contained an electric vehicle (EV), which follows one of two different schedules.

The forecast algorithm is able to perform more accurate than both benchmarks (last day persistence and last equal weekday persistence), at a forecast horizon of $24 \mathrm{~h}$. At the test procedure, the forecast algorithm shows a lower mean average percentage error (MAPE) compared to these benchmarks. Although, a tendency to underestimate values is indicated by the negative mean bias error, leaving room for improvement. If compared to a minute wise forecast, the developed forecast algorithm performs worse. Thus, a combination of the minute wise forecast and the developed forecast algorithm is integrated into the purposed energy management system (EMS) to enable precise operation and planning.

It is shown that load forecast uncertainty affects the electricity cost of a household, depending on the available storage capacities, using a constant price of energy and feed in tariff. If the EV is used as a primary vehicle (mainly trips from and to work), increasing the stationary storage capacity leads to an increased significance of forecast uncertainties. Without stationary storage capacity, the forecast uncertainties barely increase the cost. With $12 \mathrm{kWh}$ stationary storage capacity, the costs are increased by around $11 \%$. If the EV is used as a secondary vehicle (short trips over the course of a day), adding more stationary storage capacity affects the impact of forecast uncertainty less than in the primary 
use case, but in general the cost increase is bigger. Without stationary storage, forecast uncertainties increases the cost by around $9 \%$. With a storage capacity of $12 \mathrm{kWh}$, the cost are increased by $14 \%$. This shows that the bigger the storage and the higher the availability of the storage during power production, the more significant accurate load forecasts becomes. Adding a PV-forecast has a similar effect as the load forecast, as it further increase the electricity cost.

Furthermore, the primary EV schedule leads to bigger electricity cost than the secondary EV. Especially without a stationary storage, the secondary EV is able to save electricity cost. In this case the EV acts like storage rather than adding additional load to the household. Without any stationary storage, a secondary EV saves around $60 €$ in almost one year compared to a primary $\mathrm{EV}$. If a $12 \mathrm{kWh}$ stationary storage is added to the household energy system, the difference between primary and secondary EV is decreased to almost zero. Because of the high saving without having a stationary storage, an EV with a secondary usage profile can be an adequate substitution for stationary storage or make smaller stationary storage devices more viable to save cost. This is also reflected in shorter payback times of a system which comprises a secondary EV instead of a primary one. This is particularly relevant for low HES capacities. However, adding stationary storage is very expensive and thus increases the payback time to a level of no overall economic benefit.

Future research addresses a more in depth investigation of uncertainties under operation. Additionally, in this research the EV is moved according to a synthetic schedule, which is known by the EMS and does not fully catch real world EV movement patterns. Forecasting the EV movement, based on real word data, could be integrated. Thus, the EMS can operate more autonomously, avoiding currently necessary user input and increasing the users' comfort. Furthermore, a comprehensive investigation on the investment and maintenance cost, especially regarding the impact of a bidirectional $\mathrm{EV}$, is necessary for an overall cost assessment.

Author Contributions: S.A. conceived and designed the simulations, analysed the results and prepared the manuscript. K.D. analysed the results and helped editing the paper. F.S. added research ideas. K.v.M. critically reviewed the draft. C.A. supervised the work.

Funding: The authors acknowledge the financial support provided by the BMWi, the Federal Ministry for Economic Affairs and Energy for funding the project Drahtlos (FKZ 03ET6076E).

Conflicts of Interest: The authors declare no conflict of interest.

\section{Abbreviations}

The following abbreviations and symbols are used in this manuscript:

\begin{tabular}{ll}
\multicolumn{2}{c}{ Abbreviations } \\
PV & Photovoltaics \\
DC & Direct Current \\
AC & Alternating Current \\
EMS & Energy Management System \\
HES & Home Energy Storage \\
EV & Electric Vehicle \\
STD & Standard Deviation \\
SoC & State of Charge \\
PoE & Price of Energy \\
FiT & Feed in Tariff \\
ANN & Artificial Neural Network \\
ARMA & Autoregressive-Moving Average \\
LSTM & Long Short-Term Memory \\
RMSE & Root Mean Square Error \\
MBE & Mean Bias Error \\
MAPE & Mean Averaged Percentage Error \\
WEKA & Waikato Environment for Knowledge Analysis \\
GLPK & GNU Linear Programming Kit
\end{tabular}


Optimization Variables

$P_{\text {grid }, j}^{+} \quad$ Power which is gained from the grid during an interval

$P_{\text {grid }, j}^{-} \quad$ Power which is fed into the grid during an interval

$P_{H E S}^{+} \quad$ Power to discharge the HES during an interval

$P_{H E S}^{-} \quad$ Power to charge the HES during an interval

$P_{E V}^{+} \quad$ Power to discharge the EV during an interval

$P_{E V}^{-} \quad$ Power to charge the EV during an interval

System Variables

PoE

FiT

Price of energy

SoC $C_{H E S, j}$

SoC $_{E V, j}$

So $C_{H E S, \min }$

So $C_{H E S, \text { max }}$

SoC $_{E V, \text { min, } j}$

SoC $_{E V, \max , j}$

$E_{H E S, \text { total }}$

$E_{E V, \text { total }}$

$P_{\text {grid,max }}^{+}$

$P_{\text {grid,max }}^{-}$

$P_{H E S, \text { max }}^{+}$

$P_{\text {HES, max }}^{-}$

$P_{E V, \text { max }}^{+}$

$P_{E V, \max }^{-}$

$\eta_{H E S}^{+}$

$\eta_{H E S}^{-}$

$\eta_{E V}^{+}$

$\eta_{E V}^{-}$

$\eta_{\text {inv }}$

$\eta_{b i, D C-D C}$

$\eta_{\text {battery,charge }}$

$\eta_{\text {battery, discharge }}$

$E_{E V \text {,ride }}$

Feed in tariff

State of charge of the HES at the end of an interval

State of charge of the EV at the end of an interval

Minimal allowed SoC of the HES

Maximal allowed SoC of the HES

Minimal allowed SoC of the EV, taken trips into account

Maximal allowed SoC of the EV, taken trips into account

Capacity of the HES battery

Capacity of the EV battery

Maximum power which can be gained from the grid

Maximum power which is allowed to be fed into the grid

Maximum discharge power of the HES

Maximum charge power of the HES

Maximum discharge power of the EV

Maximum charge power of the EV

Discharge efficiency of the HES

Charge efficiency of the HES

Discharge efficiency of the EV

Charge efficiency of the EV

Efficiency of the inverters (a subcomponent of the HES and EV)

Efficiency of the wireless charging device (a subcomponent of the EV)

Efficiency of charging the batteries (relevant for the HES and EV)

Efficiency of discharging the batteries (relevant for the HES and EV )

Simulation related Variables

$\Delta t_{j} \quad$ Time interval length

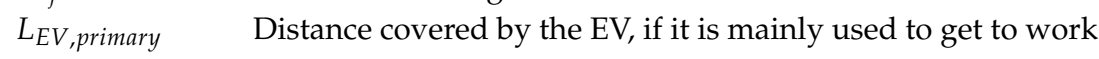

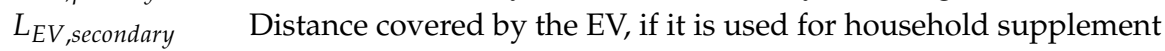

$\Delta C_{\text {schedule }}$

Lump sum to compare results from the different EV schedules

\section{Appendix A.}

\section{Appendix A.1. Primary EV Schedule}

Table A1. Primary EV schedule for a working-day.

\begin{tabular}{ccccc}
\hline Description & Departure (hh:mm) & Duration $(\mathbf{h})$ & Distance $\mathbf{( k m )}$ & Frequency (\% of days) \\
\hline Ride 1 & $08: 00$ & 9.25 & 28.8 & 100 \\
Ride 2 & $18: 00$ & 2.5 & 28.8 & 5 \\
\hline
\end{tabular}

Table A2. Primary EV schedule for a holiday or weekend-day.

\begin{tabular}{ccccc}
\hline Description & Departure (hh:mm) & Duration (h) & Distance (km) & Frequency (\% of days) \\
\hline Ride 1 & $14: 00$ & 3 & mean $=28.8$ & 75 \\
\hline
\end{tabular}


Appendix A.2. Secondary EV Schedule

Table A3. Secondary EV schedule for a week-day.

\begin{tabular}{ccccc}
\hline Description & Departure (hh:mm) & Duration $\mathbf{( h )}$ & Distance $\mathbf{( k m )}$ & Frequency (\% of days) \\
\hline Ride 1 & $07: 45$ & 0.5 & 8 & 100 \\
Ride 2 & $10: 00$ & 1 & 10 & 25 \\
Ride 3a & $12: 15$ & 1 & 10 & 50 \\
Ride 3b & $12: 45$ & 0.5 & 8 & 50 \\
Ride 4 & $17: 00$ & 1 & 10 & 25 \\
\hline
\end{tabular}

\section{References}

1. Bauer, C.; Hofer, J.; Althaus, H.; Del Duce, A.; Simons, A. The environmental performance of current and future passenger vehicles: Life cycle assessment based on a novel scenario analysis framework. Appl. Energy 2015, 157, 871-883. [CrossRef]

2. Painuly, J. Barriers to renewable energy penetration; a framework for analysis. Renew. Energy 2011, 24, 73-89. [CrossRef]

3. Chavali, P.; Yang, P.; Nehorai, A. A distributed algorithm of appliance scheduling for home energy management system. IEEE Trans. Smart Grid 2014, 5, 282-290. [CrossRef]

4. Kanchev, H.; Di, L.; Colas, F.; Lazarov, V.; Francois, B. Energy Management and Operational Planning of a Microgrid With a PV-Based Active Generator for Smart Grid Applications. IEEE Trans. Ind. Electron. 2011, 58, 4583-4592. [CrossRef]

5. van der Meer, D.; Chandra Mouli, G.R.; Morales-España Mouli, G.; Elizondo, L.R.; Bauer, P. Energy Management System with PV Power Forecast to Optimally Charge EVs at the Workplace. IEEE Trans. Ind. Inform. 2016, 10, 311-320. [CrossRef]

6. Kusakana, K. Energy management of a grid-connected hydrokinetic system under Time of Use tariff. Renew. Energy 2017, 101, 1325-1333. [CrossRef]

7. Bai, H.; Miao, S.; Ran, X.; Ye, C. Optimal dispatch strategy of a virtual power plant containing battery switch stations in a unified electricity market. Energies 2015, 8, 2268-2289. [CrossRef]

8. El-Baz, W.; Tzscheutschler, P. Autonomous coordination of smart buildings in microgrids based on a double-sided auction. In Proceedings of the 2017 IEEE Power \& Energy Society General Meeting, Chicago, IL, USA, 16-20 July 2017; pp. 1-5. [CrossRef]

9. Talha, M.; Saeed, M.S.; Ran, X.; Mohiuddin, G.; Ahmad, M.; Nazar, M.J.; Javaid, N. Energy Optimization in Home Energy Management System using Artificial Fish Swarm Algorithm and Genetic Algorithm. In Proceedings of the International Conference on Intelligent Networking and Collaborative Systems, Toronto, ON, Canada, 24-26 August 2017; pp. 203-213. [CrossRef]

10. Anvari-Moghaddam, A.; Rahimi-Kian, A.; Mirian, M.S.; Guerrero, J.M. A multi-agent based energy management solution for integrated buildings and microgrid system. Appl. Energy 2017, 203, 41-56. [CrossRef]

11. François-Lavet, V.; Taralla, D.; Ernst, D.; Fonteneau, R. Deep reinforcement learning solutions for energy microgrids management. In Proceedings of the European Workshop on Reinforcement Learning (EWRL 2016), Barcelona, Spain, 3-4 December 2016.

12. Rigo-Mariani, R.; Sareni, B.; Roboam, X.; Turpin, C. Optimal power dispatching strategies in smart-microgrids with storage. Renew. Sustain. Energy Rev. 2014, 40, 649-658. [CrossRef]

13. Rottondi, C.; Duchon, M.; Koss, D.; Palamarciuc, A.; Pitì, A.; Verticale, G.; Schätz, B. An Energy Management Service for the Smart Office. Energies 2015, 8, 11667-11684. [CrossRef]

14. Rahbar, K.; Xu, J.; Zhang, R. Real-time energy storage management for renewable integration in microgrid: An off-line optimization approach. IEEE Trans. Smart Grid 2015, 6, 124-134. [CrossRef]

15. Wright, A.; Firth, S. The nature of domestic electricity-loads and effects of time averaging on statistics on-site generation calculations. Appl. Energy 2007, 89, 389-403. [CrossRef]

16. Humeau, S.; Wijaya, T.K.; Vasirani, M.; Aberer, K. Electricity load forecasting for residential users: Exploiting aggregation and correlation between households. In Proceedings of the Sustainable Internet and ICT for Sustainability (SustainIT), Palermo, Italy, 30-31 October 2013; pp. 1-6. 
17. Park, D.C.; El-Sharkawi, M.A.; Marks II, R.J.; Atlas, L.E.; Damborg, M.J. Electric load forecasting using an artificial neural network. IEEE Trans. Power Syst. 1991, 6, 442-449. [CrossRef]

18. Feinberg, E.A.; Genethliou, D. Load forecasting. In Applied Mathematics for Restructured Electric Power Systems; Springer: Berlin, Germany, 2005; pp. 269-285, ISBN 978-0-387-23470-0.

19. Ali, D.; Yohanna, M.; Puwu, M.I.; Garkida, B.M. Long-term load forecast modelling using a fuzzy logic approach. Pac. Sci. Rev. 2016, 18, 123-127. [CrossRef]

20. Hernández, L.; Baladrón, C.; Aguiar, J.M.; Carro B.; Sánchez-Esguevillas, A.; Lloret, J. Artificial neural networks for short-term load forecasting in microgrids environment. Energy 2014, 75, 252-264. [CrossRef]

21. Ruiz-Abellón, M.C.; Gabaldón, A.; Guillamón, A. Load Forecasting for a Campus University Using Ensemble Methods Based on Regression Trees. Energies 2018, 11, 2038. [CrossRef]

22. Vazquez, R.; Amaris, H.; Alonso, M.; Lopez, G.; Moreno, J.I.; Olmeda, D.; Coca, J. Assessment of an adaptive load forecasting methodology in a smart grid demonstration project. Energies 2017, 10, 190. [CrossRef]

23. Kong, W.; Dong, Z.Y.; Hill, D.J.; Luo, F.; Xu, Y. Short-Term Residential Load Forecasting based on Resident Behaviour Learning. IEEE Trans. Power Syst. 2018, 33, 1087-1088. [CrossRef]

24. BDEW Bundesverband der Energie-und Wasserwirtschaft e.V. BDEW-Strompreisanalyse Mai 2017 Haushalte und Industrie. Available online: https://www.bdew.de/media/documents/1805018_BDEWStrompreisanalyse-Mai-2018.pdf (accessed on 20 June 2018).

25. Bundesnetzagentur-Presse Fördersätze für Photovoltaik-Anlagen Sinken Leicht, 2017. Available online: https:/ / www.bundesnetzagentur.de/SharedDocs/Pressemitteilungen/DE/2017/02052017_PV.html (accessed on 17 June 2018).

26. Everts, J.; Krismer, F.; Van Den Keybus, J.; Driesen, J.; Kolar, J.W. Optimal ZVS modulation of single-phase single-stage bidirectional DAB AC-DC converters. IEEE Trans. Power Electron. 2014, 29, 3954-3970. [CrossRef]

27. Zheng, C.; Lai, J.-S.; Chen, R.; Faraci, W.E.; Zahid, Z.U.; Gu, B.; Zhang, L.; Lisi, G.; Anderson, D. High-efficiency contactless power transfer system for electric vehicle battery charging application. IEEE J. Emerg. Sel. Top. Power Electron. 2015, 3, 65-74. [CrossRef]

28. Safoutin, M.; Cherry, J.; McDonald, J.; Lee, S. Effect of Current and SOC on Round-Trip Energy Efficiency of a Lithium-Iron Phosphate (LiFePO4) Battery Pack; SAE Paper 2015-01-1186; SAE International: Warrendale, PA, USA, 2015; doi:10.4271/2015-01-1186.

29. Hall, M.; Frank, E.; Holmes, G.; Pfahringer, B.; Reutemann, P.; Witten, I.H. The WEKA Data Mining Software: An Update. SIGKDD Explor. Newslett. 2009, 11, 10-18. [CrossRef]

30. Heaton, J. Encog: Library of Interchangeable Machine Learning Models for Java and C\#. J. Mach. Learn. Res. 2015, 16, 1243-1247.

31. Makhorin, A. The GNU Linear Programming Kit (GLPK) GNU Software Foun- Dation. 2000. Available online: http:/ / www.gnu.org/software/glpk/glpk.html (accessed on 15 September 2018).

32. Fraunhofer ISE. Current and Future Cost of Photovoltaics. Long-Term Scenarios for Market Development, System Prices and LCOE of UtilityScale PV Systems, Study on Behalf of Agoram Energiewende, Freiburg and Berlin. 2015. Available online: https://www.ise.fraunhofer.de/content/dam/ise/de/documents/ publications /studies / AgoraEnergiewende_Current_and_Future_Cost_of_PV_Feb2015_web.pdf (accessed on 18 September 2018).

33. Figgener, J.; Haberschusz, D.; Kairies, K.-P.; Wessels, O.; Tepe, B.; Sauer, D.U. Wissenschaftliches Mess- und Evaluierungsprogramm Solarstromspeicher 2.0. Available online: http:/ /www.speichermonitoring.de/ fileadmin/user_upload/Speichermonitoring \_Jahresbericht_2018_ISEA_RWTH_Aachen.pdf (accessed on 24 September 2018).

34. Gartman, D. Three Ages of the Automobile: The Cultural Logics of the Car. Theory Cult. Soc. 2004, 21, 169-195. [CrossRef]

(C) 2018 by the authors. Licensee MDPI, Basel, Switzerland. This article is an open access article distributed under the terms and conditions of the Creative Commons Attribution (CC BY) license (http://creativecommons.org/licenses/by/4.0/). 